\title{
Creation of Ventricular Septal Defects on the Beating Heart in a New Pig Model
}

\author{
R. Kozlik-Feldmann ${ }^{a} \quad$ N. Lang ${ }^{a} \quad$ R. Sodian ${ }^{b} \quad$ R. Aumann ${ }^{a} \quad$ D. Rassoulian ${ }^{b}$ \\ M. Hinterseer ${ }^{c} \quad$ C. Schmitz ${ }^{b} \quad$ H. Netz ${ }^{a}$ \\ Departments of a Pediatric Cardiology ${ }^{b}$ Cardiac Surgery, and ${ }^{\mathrm{c} C}$ Cardiology, University Hospital Grosshadern, \\ Ludwig Maximilian University, Munich, Germany
}

\section{Key Words}

Animal models • Muscular ventricular septal defects • Muscular ventricular septal defect closure, therapeutic strategies

\begin{abstract}
Background/Aims: So far, surgical and interventional therapies for muscular ventricular septal defects (mVSDs) beyond the moderator band have had their limitations. Thus, alternative therapeutic strategies should be developed. We present a new animal model for the evaluation of such strategies. Methods: In a pig model $(\mathrm{n}=9)$, anterolateral thoracotomy was performed for exposure of the left ventricle. mVSDs were created under two- and three-dimensional echocardiography with a 7.5-mm sharp punch instrument, which was forwarded via a left ventricular puncture without extracorporeal circulation. Results: Creation of mVSDs was successful in all animals $(n=9)$ confirmed by echocardiography, hemodynamic measurements and autopsy. The defects were located in the midmuscular $(n=4)$, apical $(n=1)$, inlet $(n=2)$ and anterior part $(n=2)$ of the muscular septum. All animals were hemodynamically stable for further procedures. The diameter and shunt volume of the mVSDs were 4.8-7.3 mm (mean: $5.9 \mathrm{~mm}$ ) and 12.9-41.3\% (mean: 22.1\%), respectively. Autopsy confirmed in all animals the creation of a substantial defect. Conclusion: The described new technique for creation of an mVSD on the beating heart in a pig model is suitable for the evaluation of new therapeutic strategies for mVSD closure.

Copyright $\odot 2008$ S. Karger AG, Basel
\end{abstract}

\section{Introduction}

Ventricular septal defects (VSDs) are the most common congenital cardiac defects, and account for approximately $20 \%$ of all congenital heart diseases [1]. They are classified according to their location in the septum [2]. Muscular VSDs (mVSDs) account for approximately 10$15 \%$ of all VSDs [3].

Hemodynamic significance depends on the size of the VSDs, the pressure in the right and left ventricle, and the pulmonary vascular resistance. The shunt volume is largely determined by the size of the defect and the pulmonary resistance. Symptoms depend on the relevance of the VSD and range from congestive heart failure to delayed growth and development, paleness, shortness of breath or arrhythmias [4]. The final stage of untreated VSDs is Eisenmenger's syndrome with irreversibly elevated pulmonary arterial pressure (PAP). Thus, therapy must be accurately timed. While most defects above the moderator band can be surgically closed by a transatrial approach from the right side, definitive treatment for complex mVSDs beyond the moderator band is still challenging, particularly in small infants. Both approaches - surgical and interventional - have their limitations. Especially, mVSDs beyond the moderator band may require left ventriculotomy, or the division of multiple important right-sided muscle bands when using a right atrial approach. This course of action is associated with longterm morbidity $[5,6]$, prolonged admission and scar formation [4]. The rate of reoperation due to residual

\section{KARGER}

Fax +41613061234

E-Mail karger@karger.ch

www.karger.com
(C) 2008 S. Karger AG, Basel 0014-312X/08/0403-0297\$24.50/0

Accessible online at: www.karger.com/esr
R. Kozlik-Feldmann

Department of Pediatric Cardiology, University Hospital Grosshadern Marchioninistrasse 15

DE-81377 Munich (Germany)

Tel. +49 897095 3942, Fax +49 897095 3943, E-Mail kozlik-f@lrz.uni-muenchen.de 


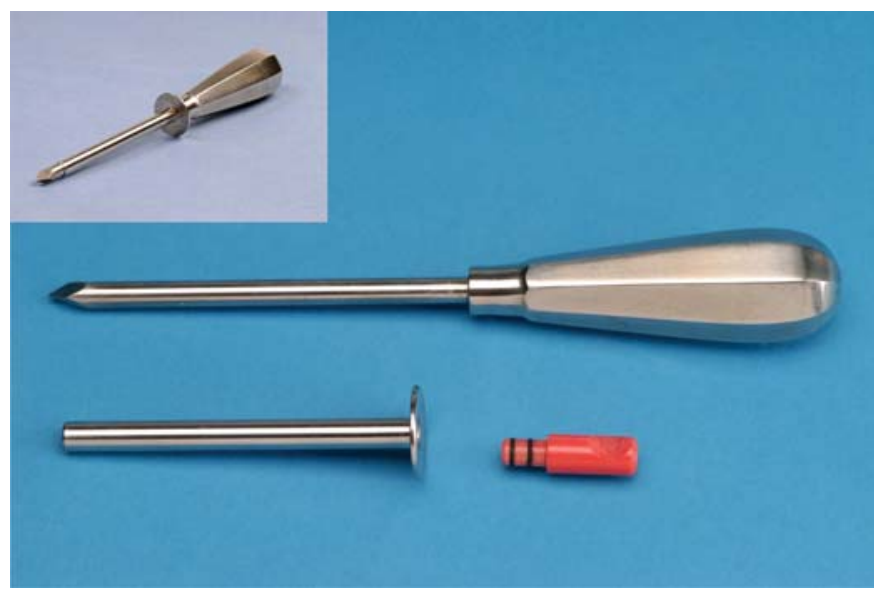

Fig. 1. The punch instrument for creation of mVSDs. It consists of three pieces: a trocar, a sharp hollow needle and a plug.

shunts after mVSD closure using right atriotomy is reported to be up to $10 \%$ [7]. Furthermore, surgery requires extracorporeal circulation (ECC), which may be associated with different adverse effects [8-10].

The alternative of interventional strategies are limited by poor vascular access, especially in small infants [11]. The use of big sheaths can cause severe rhythm disturbances and hemodynamic deterioration during the procedure. The most commonly used Amplatzer devices are working with a stenting mechanism and are associated with significant arrhythmias, hemodynamic impairment, valve injury or incomplete closure $[12,13]$.

Thus, exploration of novel therapeutic strategies is reasonable. For assessment, a valid animal model for evaluation and establishment of new approaches has not yet been published. Here we report about a new technique to create mVSDs on the beating heart in pigs.

\section{Materials and Methods}

\section{Animals}

We used German Landrace piglets of either sex $(n=9$, weight $20-30 \mathrm{~kg}$ ), which were purchased from the local farm of the University of Munich (Oberschleissheim, Germany). The experimental protocol was approved by the local Governmental Commission on the Care and Use of Animals. The animals received care in compliance with the Guide for the Care and Use of Laboratory Animals. All experiments were performed in the Laboratory of Surgical Research, Walter Brendel Center for Experimental Medicine, at the Ludwig Maximilian University of Munich, Germany.

\section{Anesthesia}

The piglets were fasted overnight and premedicated intramuscularly with $500 \mathrm{mg}$ ketamine, $10 \mathrm{mg} / \mathrm{kg}$ body weight azaperone and $0.5 \mathrm{mg}$ atropine. Midazolam $(0.1 \mathrm{mg} / \mathrm{kg}$ body weight) was administered intravenously via an ear vein. The animals were intubated with a $6.5-\mathrm{mm}$ tube and ventilated with an $\mathrm{FiO}_{2}$ of $50 \%$. General anesthesia was induced and maintained with propofol (1.5-2 $\mathrm{mg} / \mathrm{kg}$ body weight $/ \mathrm{h}$, maintenance $10 \mathrm{mg} / \mathrm{kg}$ body weight/ h) and fentanyl $(0.02 \mathrm{mg} / \mathrm{kg}$ body weight $/ \mathrm{h}$, maintenance 0.045 $\mathrm{mg} / \mathrm{kg}$ body weight/h). Ventilation was adjusted to keep arterial $\mathrm{pCO}_{2}$ between 35 and $45 \mathrm{~mm} \mathrm{Hg}$. Arterial blood samples were obtained for analyses of $\mathrm{pO}_{2}, \mathrm{pCO}_{2}$ and $\mathrm{pH}$. Prior to thoracotomy, muscle paralysis was induced with pancuronium bromide, 0.1 $\mathrm{mg} / \mathrm{kg}$ body weight intravenously, with single additional doses if necessary.

Ringer solution was given at a base rate of $10 \mathrm{ml} / \mathrm{kg}$ body weight/h. Hydroxyethyl starch $6 \%$ was administered in case of relevant blood loss. Oxygenation, ECG and temperature were monitored continuously throughout the study.

Amiodarone $(20 \mathrm{mg} / \mathrm{kg}$ body weight/day) and magnesium ( $3 \mathrm{mmol}$ ) were given intravenously throughout the whole study to prevent ventricular arrhythmias.

\section{Surgical Preparation}

First all animals were shaved for thoracotomy and neck dissection on the right side. The external carotid artery and the jugular vein were dissected, and cannulated with a 9 -french and an 11-french introducer sheath, respectively, for continuous arterial (AP) and central venous pressure (CVP) monitoring.

Animals were placed in dorsolateral recumbency with the left side upward. Left 4 th intercostal thoracotomy was performed and the heart was exposed by opening the pericardium.

\section{Imaging}

For imaging, two- and three-dimensional echocardiography was used. For two-dimensional echocardiography (Sonos 5500, Philips Medical Systems, The Netherlands), a 5-MHz transesophageal echocardiographic probe was put behind the beating heart via an incision in the 6 th intercostal space. Three-dimensional echocardiography was performed epicardially by using the X7-2 matrix transducer of the IE33 Ultrasound System (Philips Medical Systems, The Netherlands).

\section{Creation of $m V S D s$}

The entire procedure was performed without the use of ECC. Creation of mVSDs was achieved using a specially designed punch instrument. It contained a trocar and a superimposed sharp hollow needle (fig. 1; Müller Instrumente GmbH, Tuttlingen, Germany). Purse-string sutures were applied on the apical left ventricular wall to minimize blood loss during the creation procedure. The instrument was inserted into the left ventricle via a left ventricular puncture (fig. $2 a$ ). Subsequently, the trocar was retrieved, and the open end of the hollow needle was closed with an appropriate plug (fig. 1, 2b).

The following procedure was done under continuous two-dimensional and three-dimensional echocardiographic control. The hollow needle was forwarded towards the muscular septum. After positioning the hollow needle at the desired portion of the septum, an mVSD was created by rotating the hollow needle continuously towards the septum. Figure 2 demonstrates the prin- 

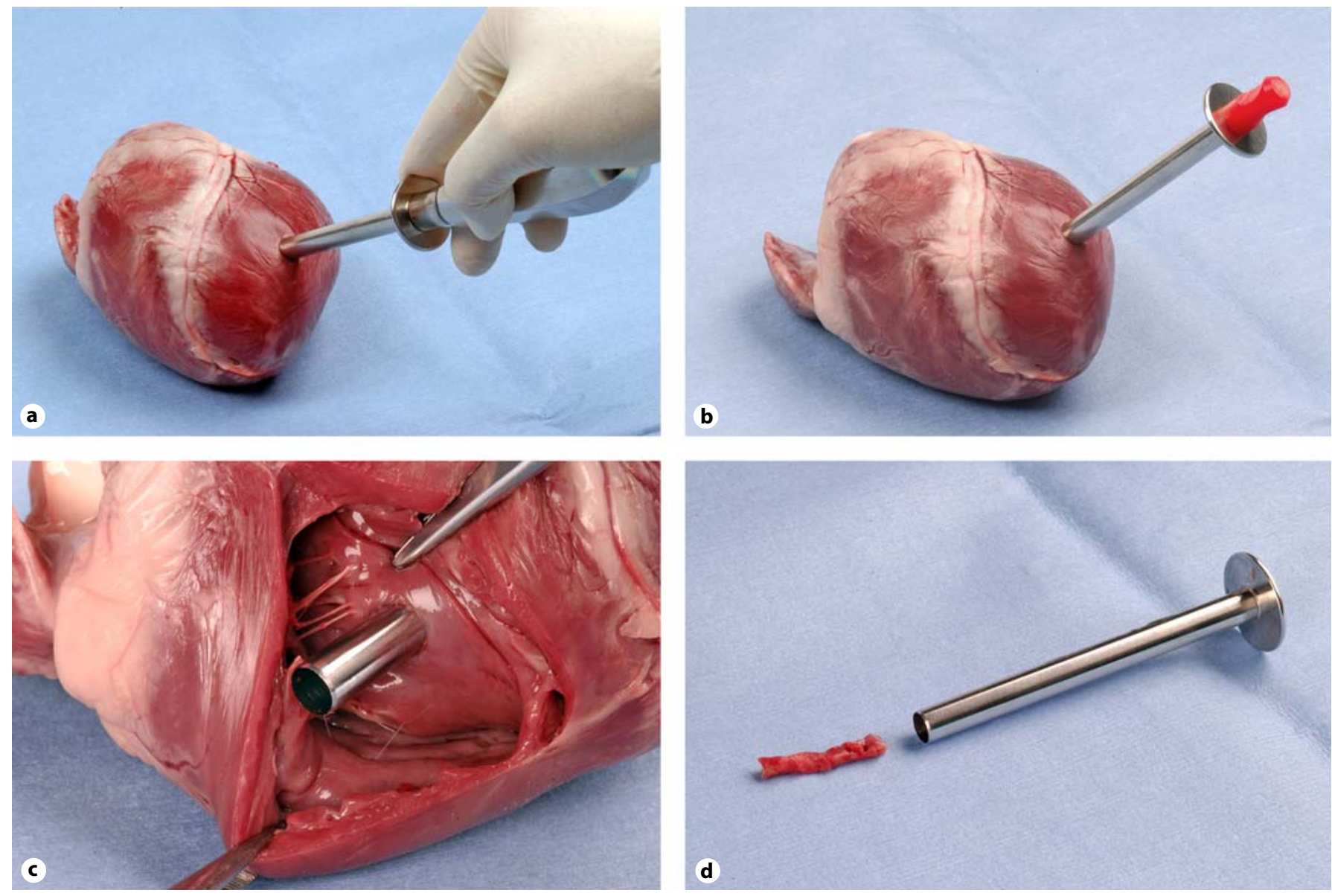

Fig. 2. Demonstration of the creation of mVSDs ex vivo. a The first step of creation of VSDs is to forward the punch instrument via a left ventricular incision into the left ventricle. $\mathbf{b}$ Afterwards the trocar is retrieved and the remaining hollow needle is closed with a plug. c The hollow needle penetrating the muscular septum is demonstrated. d Our method creates a substantial defect into the muscular septum.

ciple of our technique ex vivo. By adjusting the position of the hollow needle the defects could be varied regarding their orientation to the inlet, anterior, middle or apical portion of the septum.

Successful creation of an mVSD was confirmed by echocardiographic visualization with sizing of the VSD and measurements of the shunt volume by the Fick method as well as explantation of the heart. Finally, animals were euthanized by an intracardial injection of $40 \mathrm{mval} \mathrm{KCl}$. Autopsy of the hearts was performed for exact location of the defects.

\section{Measurements}

Arterial blood samples were obtained every $60 \mathrm{~min}$ to control appropriate ventilation. Heart rate, AP and CVP were monitored continuously. Mean AP (MAP), CVP, PAP and pulmonary capillary wedge pressure (PCWP) were obtained at baseline, before thoracotomy and after creation of the shunt.

Ventricular Septal Defects on the Beating Heart in a New Pig Model

\section{Statistical Analysis}

Values are presented as means \pm standard deviation. For comparison of different groups, the paired t test was used. A p value $<0.05$ was considered as statistically significant.

\section{Results}

Basal echocardiography excluded cardiac defects and valve insufficiencies in the animals. The surgical procedure was well tolerated by all animals $(n=9)$. Hemodynamic parameters were stable during the surgical procedure in all animals without administration of catecholamines. There was a slight decrease in MAP and CVP values without statistical significance (fig. 3a).

Eur Surg Res 2008;40:297-303 

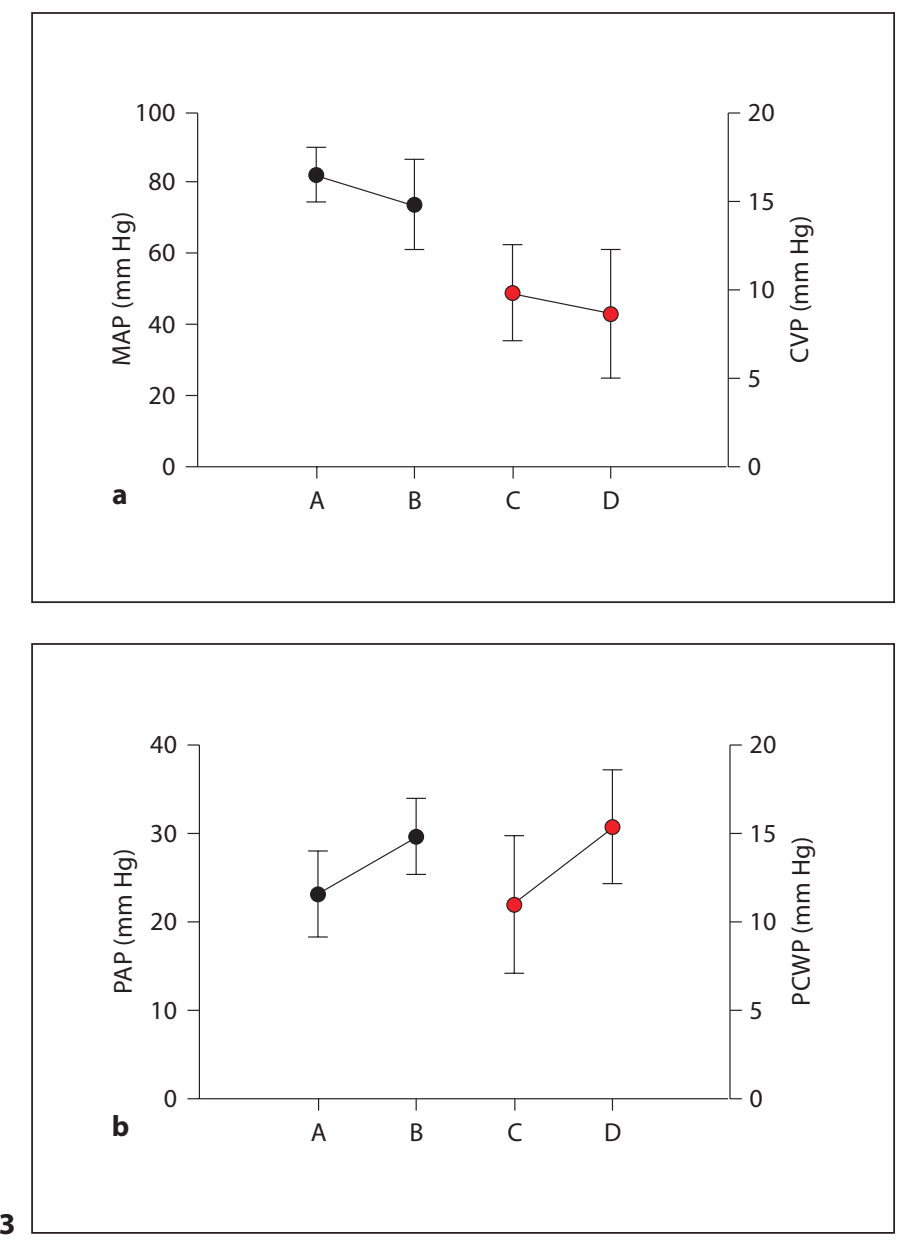

Fig. 3. Hemodynamics throughout the experiment. MAP (A, B) and $\operatorname{CVP}(\mathrm{C}, \mathrm{D})(\mathbf{a})$, and $\operatorname{PAP}(\mathrm{A}, \mathrm{B})$ and $\mathrm{PCWP}(\mathrm{C}, \mathrm{D})(\mathbf{b})$ measurements before $(A, C)$ and after creation $(B, D)$ of the defect. It is obvious that there is only a slight decrease in MAP and CVP. b Development of a mild pulmonary hypertension and left ventricular dysfunction.

Fig. 4. A representative midmuscular VSD without (a) and with (b) residual tissue in two-dimensional echocardiography ( $\mathrm{LV}=$ left ventricle; $\mathrm{RV}=$ right ventricle). Strong left-to-right shunts are seen in both panels. Flow away from the transducer is coded blue, flow towards the transducer is coded red. b There is no obstruction of the mVSD by the residual tissue at its edge.

Fig. 5. A representative midmuscular VSD in three-dimensional echocardiography. A piece of muscular septum is shown with evident left-to-right shunt.

PAP and PCWP values showed a trend towards an increase although not statistically significant. Accordingly, there was a development of mild pulmonary hypertension and left ventricular dysfunction (fig. 3b).
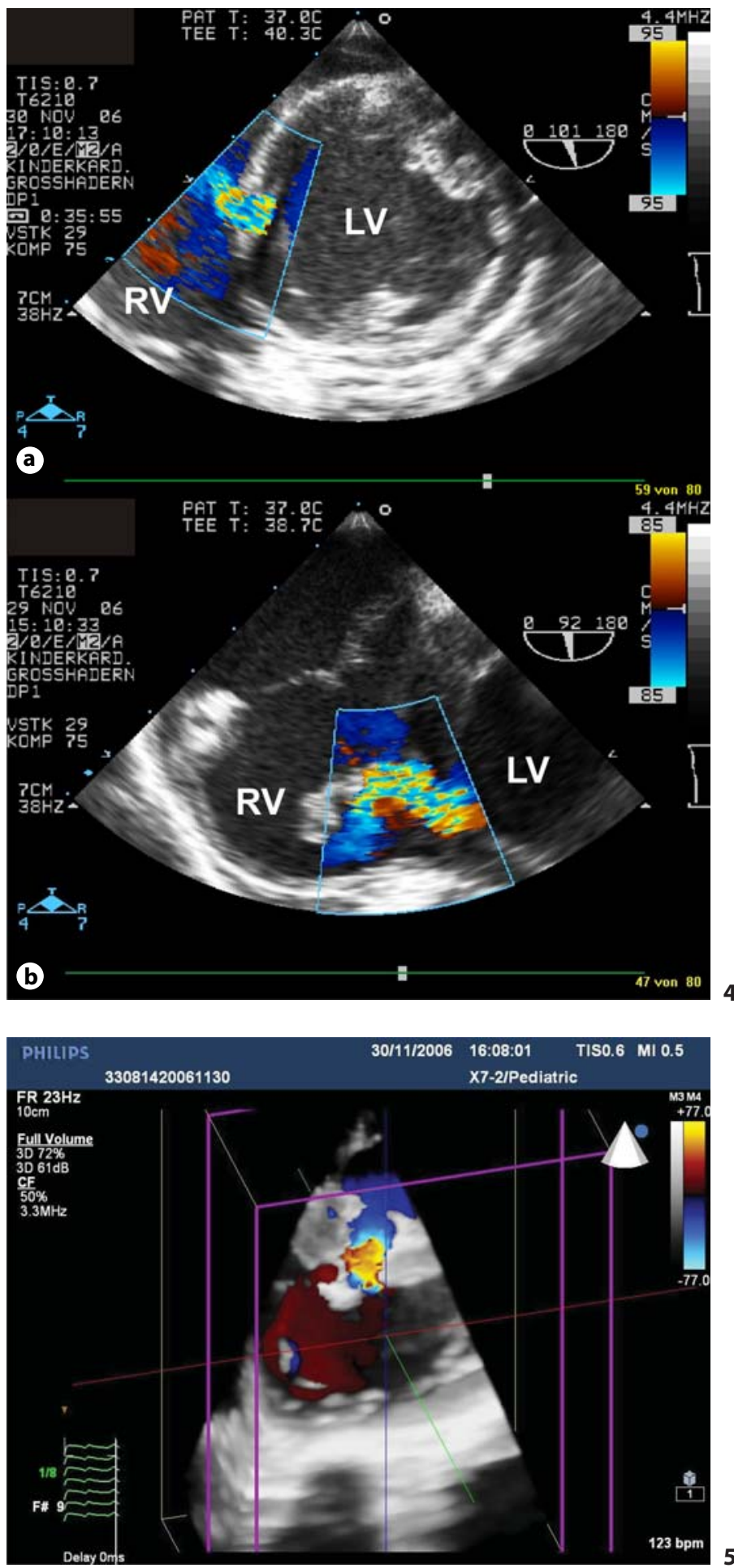

Creation of an mVSD was successful in all animals confirmed by echocardiography and measurement of the shunt volume (fig. 4, 5). The echocardiographic diameter of the mVSDs ranged from 4.8 to $7.3 \mathrm{~mm}(5.9 \pm 0.9 \mathrm{~mm})$; 
shunt volumes were calculated between 12.9 and $41.3 \%$ (mean $22.1 \pm 16.0 \%$ ). The Qp:Qs ratios varied from 1.2:1 to 1.7:1. Explantation of the heart revealed the exact location of the VSDs (fig. 6). The defects were located in the distal apical muscular $(\mathrm{n}=1)$, anterior muscular $(\mathrm{n}=$ $2)$, midmuscular $(\mathrm{n}=4)$, and inlet muscular $(\mathrm{n}=2)$ region of the muscular septum (table 1). Furthermore, it was obvious that substantial defects were created. A correlation of diameter and shunt volumes was not found.

There was a small muscle bridge left at one edge of the defect on the right side of the septum after the procedure in 8 out of 9 animals (fig. 4b). Substantial swelling of the surrounding area was noted in all animals.

\section{Discussion}

The present study describes a new technique to create mVSDs without using ECC in pigs. This animal model serves to evaluate and establish new interventional and hybrid therapies for closure of mVSDs.

The conventional therapy of mVSDs is surgery. Muscular defects above the moderator band can be treated by a transatrial approach. However, mVSDs localized beyond the moderator band still remain a technical challenge. If a primary repair is not possible, a pulmonary banding can be done in order to delay definitive surgery. In these cases, left ventriculotomy is often performed and can result in long-term complications [5, 6]. Surgery is generally associated with side effects such as prolonged admission, scar formation, and discomfort [4]. Furthermore, surgery requires ECC which may be associated with various adverse effects such as impaired neurological development $[9,10]$ or systemic inflammatory response syndrome [8]. Recently, interventional therapy for closure of mVSDs has shown promising results $[12,14$, 15]. However, major limitations are the challenging procedures, low patient weight or poor vascular access [11]. Additionally, rhythm disturbances and hemodynamic instability especially in small infants have been reported [14].

Hybrid therapy, combining the advantages of surgical and interventional techniques, is a promising approach for closure of mVSDs [16-19]. Besides advantages, there are still complications such as device embolization into the aorta or valve injuries.

Thus, new therapeutic strategies for mVSD closure have to be developed. These new approaches have to be tested in an animal model prior to human application. Amin et al. [20] reported of the creation of mVSDs in dogs
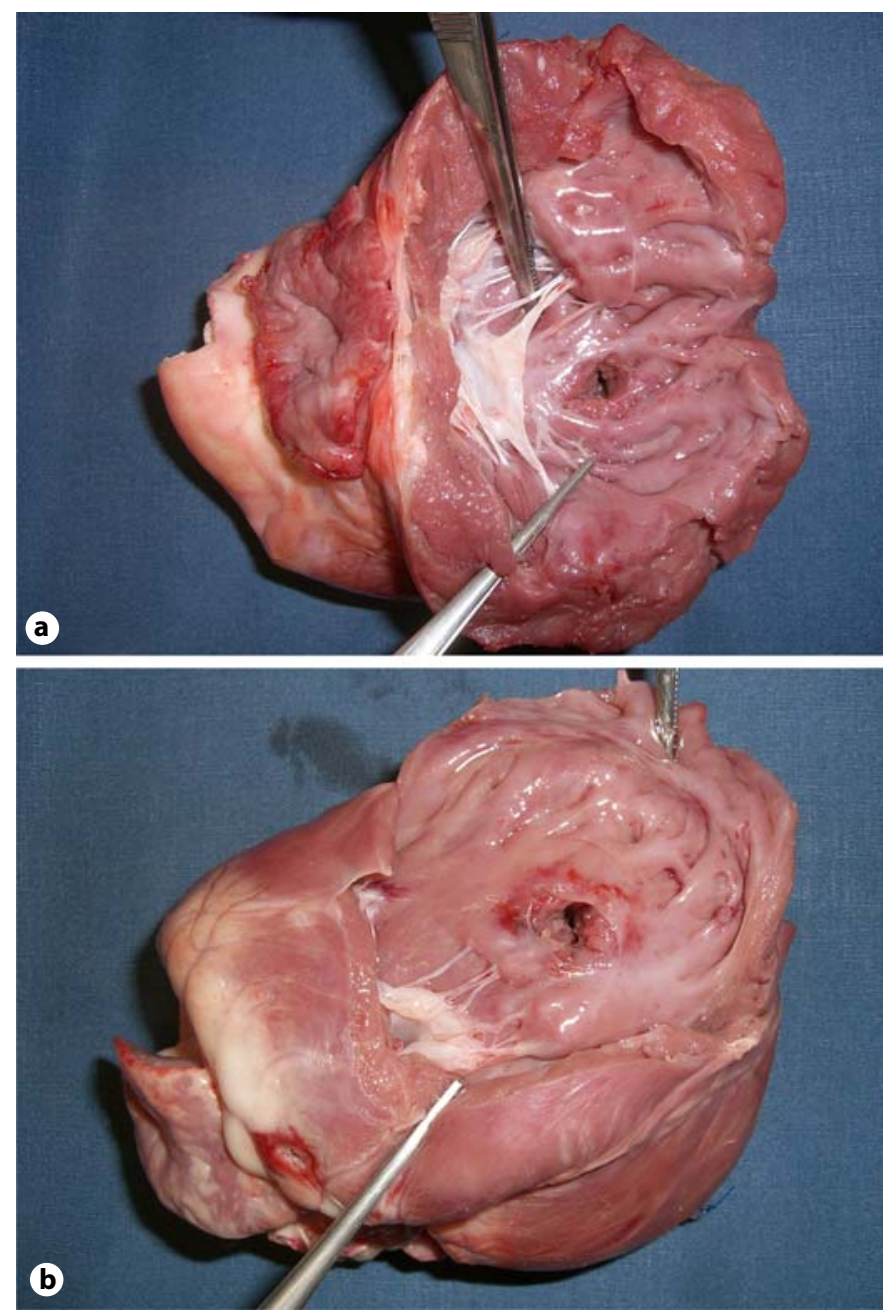

Fig. 6. Demonstration of a representative $\mathrm{mVSD}$ in an explanted heart. a mVSD from the right ventricular side. $\mathbf{b}$ mVSD from the left ventricular side. It is obvious that a substantial mVSD was created.

Table 1. Size of the mVSDs and the location in the septum

\begin{tabular}{lll}
\hline Pig No. & Diameter, mm & Location \\
\hline 1 & 5.0 & midmuscular \\
2 & 6.3 & inlet muscular \\
3 & 4.8 & anterior muscular \\
4 & 4.8 & apical \\
5 & 6.7 & midmuscular \\
6 & 6.3 & midmuscular \\
7 & 5.1 & anterior muscular \\
8 & 6.0 & midmuscular \\
9 & 7.3 & inlet muscular \\
\hline
\end{tabular}


with an intraoperative success rate of $85 \%$. There are relevant differences between the animal model described by Amin et al. and ours. They used median sternotomy. Furthermore, they created the mVSD from the right ventricular side.

We believe that pigs can hardly survive after median sternotomy, as fixation of the sternum is nearly impossible. Thus, we established an animal model with left anterolateral thoracotomy as an approach. Consequently, the mVSDs were created from the left ventricular side.

We demonstrate the feasibility of a novel technique for creation of mVSDs in a pig model. Echocardiographic visualization of the procedure with a transesophageal echocardiography probe put behind the beating heart was excellent and comparable to conventional transesophageal echocardiography. The incision for the probe can be used for insertion of a chest drain in a chronic animal study. Echocardiography and measurements of shunt volumes after the procedure confirmed successful and reproducible creation in $100 \%$ in contrast to $85 \%$ in the dog animal model [13].

We used piglets weighing up to $20-30 \mathrm{~kg}$ to evaluate a general feasibility of our technique. The punch instrument may easily be modified from standard instruments. The diameter can be changed as needed. We believe that the same technique may also be used for creation of mVSDs in piglets weighing below $10 \mathrm{~kg}$ with smaller punch instruments. However, very young piglets may become more hemodynamically instable than older ones. Thus, the mVSDs should be induced by an experienced person. We are aware that therapeutic strategies should also be evaluated in piglets weighing below $10 \mathrm{~kg}$.

We decided to use a 7.5- $\mathrm{mm}$ punch to avoid acute pulmonary hypertension and left ventricular dysfunction with acute deterioration of the circulation. We observed a discrepancy between unexpectedly small Qp:Qs ratios and substantial defects in autopsy. This may be due to myocardial swelling which could be observed after the procedure in echocardiography. Development of pulmonary hypertension was only mild. After vanishing of the edema the shunts might increase. Consequently, development of relevant pulmonary hypertension seems likely. If in acute experimental designs bigger shunts are recommended, the punch instrument should have an increased diameter of up to $10 \mathrm{~mm}$. In our general feasibility studies the animals with a $7.5-\mathrm{mm}$ punch showed excellent hemodynamic stability without relevant pulmonary hypertension or left ventricular dysfunction. Thus, evaluating new techniques in the same session seems possible.
Our model can be used for evaluating new therapeutic strategies for mVSD closure prior to human application. An acute and chronic design of these experiments seems to be possible.

In an acute design, the mVSDs can be closed during the same session. Because of the excellent hemodynamic stability of the pigs, therapeutic strategies can extensively be tested.

Furthermore, it might also be possible to end the operation after creation of the defect, and extubate the animals. After animals recovered from surgery, maybe after 3-6 weeks, evaluation of therapeutic strategies could be done in a second session.

Furthermore, a chronic design of the experiments also seems to be feasible. This was one reason why we used anterolateral thoracotomy instead of median sternotomy. Thus, animals can survive after closing the mVSD with a new technique. Long-term consequences of new techniques such as efficacy of the technique or left ventricular dysfunction can be evaluated. Recently, improvements in myocardial tissue engineering, e.g. construction of contractile patches, have been made. Until now, primarily large animal models are needed for evaluation of these patches. Our animal model can also serve this purpose. Thus, this pig model can be used to evaluate and establish novel therapeutic strategies either during the same operation or in a second session.

Another application area could be the investigation of pulmonary hypertension. We believe that it might be possible to wake up the animals after creation of the VSD. This would allow to reinvestigate them after 4-6 weeks. Then, development of pulmonary hypertension seems likely as the edema may vanish after 2 weeks and the shunt volume increases.

In addition, we saw a small tissue bridge at one edge of the mVSD at the right side of the septum after creation of the defect. The reason for this finding is the angle between the punch instrument and the muscular septum. Usually, it will not be $90^{\circ}$ and a small tissue bridge will remain between the muscular material punched out and the septum on the right ventricular side. Because of the left-to-right shunt it is unlikely that this tissue will obstruct the VSD. In a chronic setting, this might cause pulmonary embolism at the segment artery level.

Autopsy of the heart revealed four different locations of the created mVSDs, so that different subtypes of mVSDs can be tested for closure. The location of the defects can be controlled by echocardiography. Apical defects are most difficult to create as the right ventricular wall can be punctured. 
In summary, we established a new technique to create mVSDs without ECC under echocardiographic guidance in a pig model. We plan to use this model to test new hybrid devices for VSD closure. We hope this information may be helpful for other authors dealing with the creation and treatment of mVSDs.

\section{Acknowledgements}

This work became possible with the financial support of the 'Elterninitiative Kinderklinik Grosshadern e.V.' and the 'Heart for Heart Foundation'. In addition, the authors thank Heinrich Beckermann (Philips Medical Systems, Germany) and Dr. Franz Freudenthal (pfm, Bolivia) for their technical support as well as Rabea Hinkel for critical comments.

\section{References}

1 Mitchell SC, Korones SB, Berendes HW: Congenital heart disease in 56,109 births. Incidence and natural history. Circulation 1971;43:323-332.

2 Soto B, Becker AE, Moulaert AJ, Lie JT, Anderson RH: Classification of ventricular septal defects. Br Heart J 1980;43:332-343.

3 Anderson RH, Lenox CC, Zuberbuhler JR: The morphology of ventricular septal defects. Perspect Pediatr Pathol 1984;8:235268.

4 Minette MS, Sahn DJ: Ventricular septal defects. Circulation 2006;114:2190-2197.

5 Pretre R, Benedikt P, Turina MI: Modified approach to close multiple apical ventricular septal defects. Eur J Cardiothorac Surg 1999; 16:683-685.

6 Wollenek G, Wyse R, Sullivan I, et al: Closure of muscular ventricular septal defects through a left ventriculotomy. Eur J Cardiothorac Surg 1996;10:595-598.

7 Kitagawa T, Durham LA III, Mosca RS, Bove EL: Techniques and results in the management of multiple ventricular septal defects. J Thorac Cardiovasc Surg 1998;115:848-856.

8 Madhok AB, Ojamaa K, Haridas V, et al: Cytokine response in children undergoing surgery for congenital heart disease. Pediatr Cardiol 2006;27:408-413.
9 Bellinger DC, Wypij D, Kuban KC, et al: Developmental and neurological status of children at 4 years of age after heart surgery with hypothermic circulatory arrest or low-flow cardiopulmonary bypass. Circulation 1999; 100:526-532.

10 Zeitlhofer J, Asenbaum S, Spiss C, et al: Central nervous system function after cardiopulmonary bypass. Eur Heart J 1993;14:885890.

11 Bacha EA, Hijazi ZM, Cao QL, et al: Hybrid pediatric cardiac surgery. Pediatr Cardiol 2005;26:315-322.

12 Holzer R, Balzer D, Cao QL, Lock K, Hijazi ZM: Device closure of muscular ventricular septal defects using the Amplatzer muscular ventricular septal defect occluder: immediate and mid-term results of a US registry. J Am Coll Cardiol 2004;43:1257-1263.

13 Thanopoulos BD, Rigby ML: Outcome of transcatheter closure of muscular ventricular septal defects with the Amplatzer ventricular septal defect occluder. Heart 2005;91: 513-516.

14 Carminati M, Butera G, Chessa M, et al: Transcatheter closure of congenital ventricular septal defects: results of the European Registry. Eur Heart J 2007;28:2361-2368.
15 Thanopoulos BD, Karanassios E, Tsaousis G, Papadopoulos GS, Stefanadis C: Catheter closure of congenital/acquired muscular VSDs and perimembranous VSDs using the Amplatzer devices. J Interv Cardiol 2003;16: 399-407.

16 Diab KA, Cao QL, Mora BN, Hijazi ZM: Device closure of muscular ventricular septal defects in infants less than one year of age using the Amplatzer devices: feasibility and outcome. Catheter Cardiovasc Interv 2007; 70:90-97.

17 Hjortdal VE, Redington AN, de Leval MR, Tsang VT: Hybrid approaches to complex congenital cardiac surgery. Eur J Cardiothorac Surg 2002;22:885-890.

18 Konstantinov IE, Coles JG: The role of intraoperative device closure in the management of muscular ventricular septal defects. Semin Thorac Cardiovasc Surg Pediatr Card Surg Annu 2003;6:84-89.

19 Butera G, Chessa M, Carminati M: Percutaneous closure of ventricular septal defects. State of the art. J Cardiovasc Med (Hagerstown) 2007;8:39-45.

20 Amin Z, Gu X, Berry JM, et al: New device for closure of muscular ventricular septal defects in a canine model. Circulation 1999; 100:320-328. 